\title{
Controllable Preparation and Characterization of Graphene-based Cobalt Oxide Nanocomposites
}

\author{
Jing Ji, Kuibo Yin, Litao Sun* \\ SEU-FEI Nano-Pico Center, Key Laboratory of MEMS of Ministry of Education, Southeast University, Nanjing, China \\ *Corresponding Author: Litao Sun, $\underline{\text { slt@seu.edu.cn }}$
}

\begin{abstract}
Here we introduce a facile hydrothermal synthesis for the controllable growth of cobalt oxide $\left(\mathrm{Co}_{3} \mathrm{O}_{4}\right)$ nanoparticles onto graphene nanostructures. The $\mathrm{Co}_{3} \mathrm{O}_{4}$ particles were monodispersive with a grain size less than $10 \mathrm{~nm}$ and homogeneously anchored on graphene sheets. The effects of oxidants, reaction temperatures, and reaction times on the microstructures of final products were investigated, respectively. The obtained material was characterized by transmission electron microscopy (TEM) and high-resolution TEM (HRTEM).
\end{abstract}

Keywords-graphene; $\mathrm{Co}_{3} \mathrm{O}_{4}$; controllable growth

\section{INTRODUCTION}

Nanosized $\mathrm{Co}_{3} \mathrm{O}_{4}$ has attracted extensive attention due to its wide potential applications in toxic gas sensors, heterogeneous catalysts, and Li-ion batteries [1-3]. However, the poor electrical conductivity of $\mathrm{Co}_{3} \mathrm{O}_{4}$ limits its practical performance [4]. One possibility to solve this problem is to incorporate $\mathrm{Co}_{3} \mathrm{O}_{4}$ nanoparticles in a composite material. Owing to the superior electrical conductivity, high surface-tovolume ratio, ultrathin thickness, structural flexibility, and chemical inertness, graphene is considered a suitable supporting membrane for nanomaterials [5]. Graphene/ $\mathrm{Co}_{3} \mathrm{O}_{4}$ nanocomposites have been synthesized successfully by using several different methods, recently. However, the $\mathrm{Co}_{3} \mathrm{O}_{4}$ nanoparticles synthesized by these methods have a wide range of grain size and/or a uneven distribution on the graphene sheets. Consequently, the synthesis method need to be further improved to obtain monodispersed nanoparticles with controllable size.

\section{EXPERIMENTS AND RESULTS}

We herein report a facile strategy to synthesize such composite of graphene-based $\mathrm{Co}_{3} \mathrm{O}_{4}$. The structural characterizations of the samples prepared with different heating times, heating temperatures and oxidants were carried out by transmission electron microscopy (TEM).

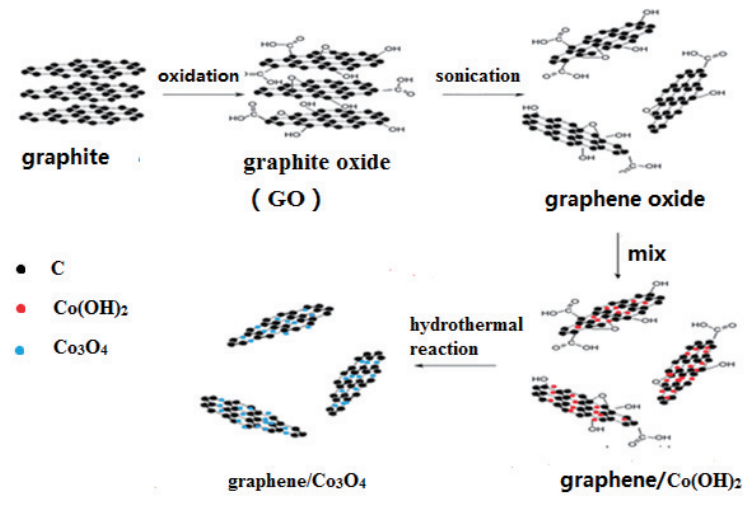

Fig. 1 mechanism of experiment.

\section{A. Synthesis of Material}

The mechanism of this experiment is illustrated at below (Fig. 1), beginning by preparing graphite oxide (GO). GO is produced by the oxidative treatment of graphite via Hummers method using $\mathrm{NaNO}_{3}, \mathrm{H}_{2} \mathrm{SO}_{4}$, and $\mathrm{KMnO}_{4}$ [6].

Then, graphite oxide was exfoliated by sonication, with the precipitation of cobalt by mixing cobalt $\left(0.24 \mathrm{~g} \mathrm{CoCl}_{2} \cdot 6 \mathrm{H}_{2} \mathrm{O}\right)$, alkali $(0.08 \mathrm{~g} \mathrm{NaOH})$ and oxidant for $0.4 \mathrm{~h}$ to form the $\mathrm{Co}(\mathrm{OH})_{2} / \mathrm{GO}$ composite. GO could not be completely exfoliated during the short sonication, but generally it contain 3-5 layers and is much thinner than graphite.

Finally, the as-prepared $\mathrm{Co}(\mathrm{OH})_{2} /$ graphene composite was treated by hydrothermal reaction to obtain the graphene $/ \mathrm{Co}_{3} \mathrm{O}_{4}$ composite. Rapid heating of GO resulted in its expansion and delamination caused by rapid evaporation of the intercalated molecule and evolution of gases produced by thermal pyrolysis of the oxygen-containing functional groups. In order to study the effect of the different reaction conditions (temperature, time, oxidant) on the hydrothermal reaction, a series of $\mathrm{Co}(\mathrm{OH})_{2}$ /graphene composite samples with variable 
TABLE I REACTION CONDITIONS WITH DIFFRERNT OXIDANTS

\begin{tabular}{|c|c|c|}
\hline Oxidant & Time (h) & Temperature $\left({ }^{\circ} \mathrm{C}\right)$ \\
\hline $30 \% \mathrm{H}_{2} \mathrm{O}_{2}$ & 15 & 150 \\
\hline $\mathrm{KClO}_{4}$ & 15 & 150 \\
\hline $\mathrm{NaNO}_{3}$ & 15 & 150 \\
\hline
\end{tabular}

TABLE II REACTION CONDITIONS WITH DIFFRERNT TEMPERTURES

\begin{tabular}{|c|c|c|}
\hline Oxidant & Time (h) & Temperature $\left({ }^{\circ} \mathrm{C}\right)$ \\
\hline $30 \% \mathrm{H}_{2} \mathrm{O}_{2}$ & 15 & 90 \\
\hline $30 \% \mathrm{H}_{2} \mathrm{O}_{2}$ & 15 & 120 \\
\hline $30 \% \mathrm{H}_{2} \mathrm{O}_{2}$ & 15 & 150 \\
\hline
\end{tabular}

TABLE III REACTION CONDITIONS WITH DIFFRERNT TIMES

\begin{tabular}{|c|c|c|}
\hline Oxidant & Time $(\mathbf{h})$ & Temperature $\left({ }^{\circ} \mathrm{C}\right)$ \\
\hline $30 \% \mathrm{H}_{2} \mathrm{O}_{2}$ & 2 & 150 \\
\hline $30 \% \mathrm{H}_{2} \mathrm{O}_{2}$ & 5 & 150 \\
\hline $30 \% \mathrm{H}_{2} \mathrm{O}_{2}$ & 10 & 150 \\
\hline $30 \% \mathrm{H}_{2} \mathrm{O}_{2}$ & 15 & 150 \\
\hline
\end{tabular}

reaction conditions was prepared. The sample was prepared with various temperatures, times and oxidants. Firstly, 30\% $\mathrm{H}_{2} \mathrm{O}_{2}, \mathrm{NaNO}_{3}$ and $\mathrm{KClO}_{4}$ were used as oxidant on the hydrothermal reaction to study the effect of oxidant (reaction conditions have been shown in Table I). Then we focused on the effect of different heating temperatures (as shown in Table II). Finally the effect of heating time was studied (reaction conditions have been shown in Table III).

\section{B. Results}

Fig. 2 shows the TEM and HRTEM images of the asprepared graphene $/ \mathrm{Co}_{3} \mathrm{O}_{4}$ composites with different oxidants. Three different oxidants including $\mathrm{NaNO}_{3}$ (Fig. 2a), $\mathrm{KClO}_{4}$ (Fig. 2b), and $30 \% \mathrm{H}_{2} \mathrm{O}_{2}$ (Fig. 2c) were used in the experiments. The reaction time $(15 \mathrm{~h})$ and temperature $\left(150{ }^{\circ} \mathrm{C}\right)$ were maintained in each treatment. It can be seen from Fig. 1 that the $\mathrm{Co}_{3} \mathrm{O}_{4}$ nanoparticles prepared with oxidant of $30 \% \mathrm{H}_{2} \mathrm{O}_{2}$ are smaller and more uniform than those prepared with $\mathrm{NaNO}_{3}$ and $\mathrm{KClO}_{4}$. From Fig. 2c one may observe that the $\mathrm{Co}_{3} \mathrm{O}_{4}$ nanoparticles have an average size of 7 $\mathrm{nm}$, and are evenly anchored on the thin graphene layers.

The effect of temperature on the microstructures of $\mathrm{Co}_{3} \mathrm{O}_{4}$ nanoparticles was investigated and the corresponding results were shown in Fig. 3. $\mathrm{H}_{2} \mathrm{O}_{2}$ was used as oxidant for $15 \mathrm{~h}$ at different reaction temperatures (Fig. 3a: $90{ }^{\circ} \mathrm{C}$, Fig. 3b: $120{ }^{\circ} \mathrm{C}$, Fig. $3 \mathrm{c}: 150{ }^{\circ} \mathrm{C}$ ). The size distributions of $\mathrm{Co}_{3} \mathrm{O}_{4}$ nanoparticles prepared at different temperatures were counted in a $100 \mathrm{~nm} \times 100 \mathrm{~nm}$ square area. The average sizes of the three samples were $5 \pm 0.4 \mathrm{~nm}\left(90{ }^{\circ} \mathrm{C}\right), 6 \pm 0.3 \mathrm{~nm}\left(120{ }^{\circ} \mathrm{C}\right)$, $7 \pm 0.5 \mathrm{~nm}\left(150^{\circ} \mathrm{C}\right)$, respectively (As shown in Fig. 4). The
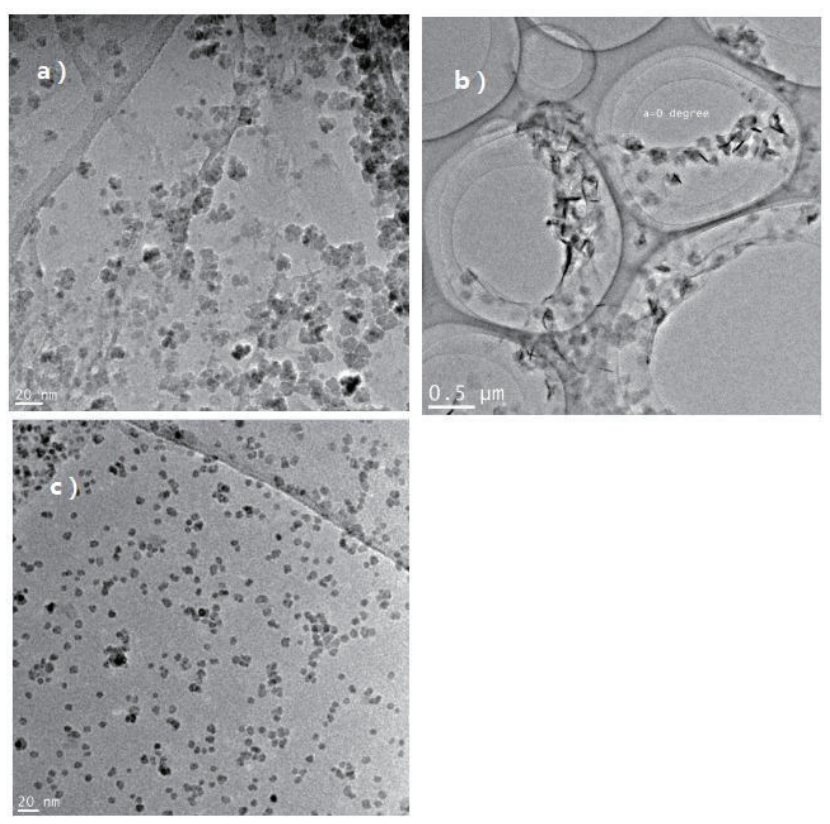

Fig. 2: TEM images of the as-prepared graphene $/ \mathrm{Co}_{3} \mathrm{O}_{4}$ composite with different oxidants. (a): $\mathrm{NaNO}_{3}$; (b): $\mathrm{KClO}_{4}$; (c): $30 \% \mathrm{H}_{2} \mathrm{O}_{2}$. (reaction time: $15 \mathrm{~h}$, reaction temperature: $150^{\circ} \mathrm{C}$ )

size distributions illustrate that the size of $\mathrm{Co}_{3} \mathrm{O}_{4}$ nanoparticles grows bigger with the reaction temperature increasing. As a consequence, the reaction temperature should be lower in order to obtain a smaller grain size of $\mathrm{Co}_{3} \mathrm{O}_{4}$. However, the lower reaction temperature will retard the reduction of graphene oxide. Therefore, $120{ }^{\circ} \mathrm{C}$ was chosen as the reaction temperature.

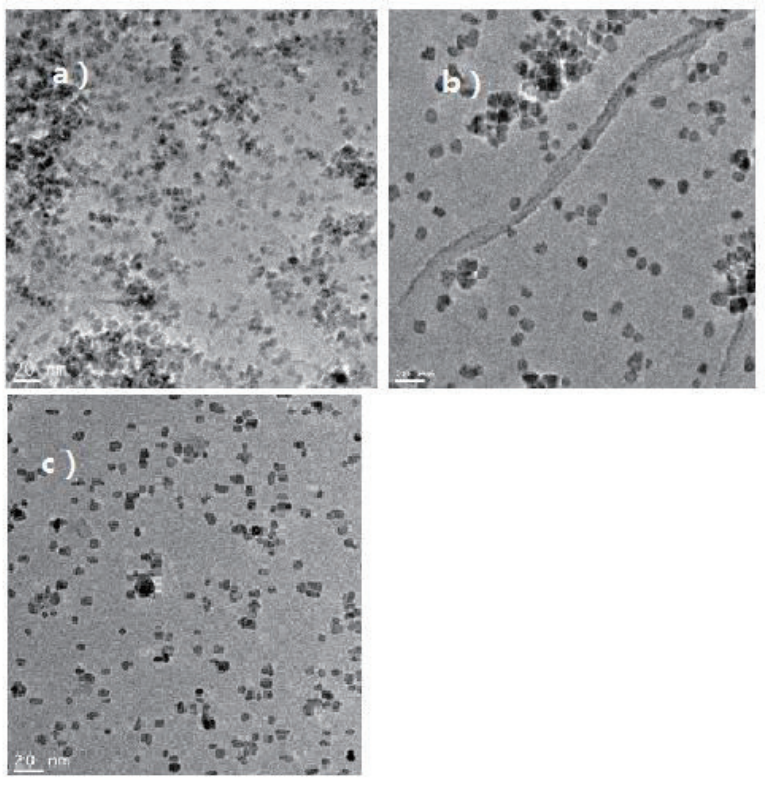

Fig. 3 TEM images of the as-prepared graphene $/ \mathrm{Co}_{3} \mathrm{O}_{4}$ composite with different heating temperatures. (a): $90^{\circ} \mathrm{C}$; (b): $120^{\circ} \mathrm{C}$; (c): $150{ }^{\circ} \mathrm{C}$. (oxidant: $30 \% \mathrm{H}_{2} \mathrm{O}_{2}$, reaction time: $15 \mathrm{~h}$ ) 


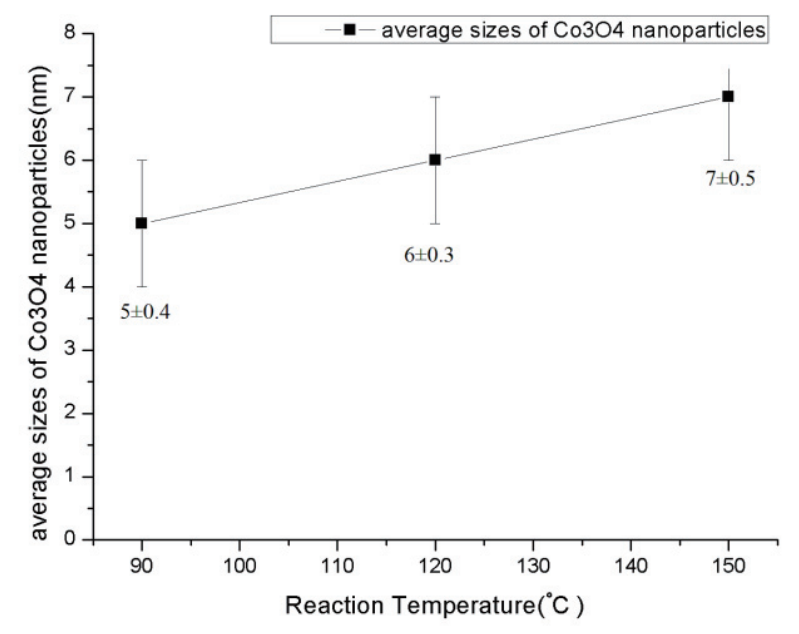

Fig. 4 the average sizes of $\mathrm{Co}_{3} \mathrm{O}_{4}$ nanoparticles with different reaction temperatures

Fig. 5 shows the TEM images of the as-prepared graphene $/ \mathrm{Co}_{3} \mathrm{O}_{4}$ composites with different reaction times (a: 2 $\mathrm{h}, \mathrm{b}: 5 \mathrm{~h}, \mathrm{c}: 10 \mathrm{~h}, \mathrm{~d}: 15 \mathrm{~h})$. It can be seen that there is a drastic change of size distribution with the reaction time varying from 5h (Fig. 5b) to $10 \mathrm{~h}$ (Fig. 5c). However, no obvious variation has been observed with the reaction time longer than $10 \mathrm{~h}$ (as shown in Fig. 6). So we deduce that, in the situation of $30 \%$ $\mathrm{H}_{2} \mathrm{O}_{2}$ as oxidant and $150{ }^{\circ} \mathrm{C}$ as reaction temperature, the $10 \mathrm{~h}$ reaction time is enough to make the reaction complete.

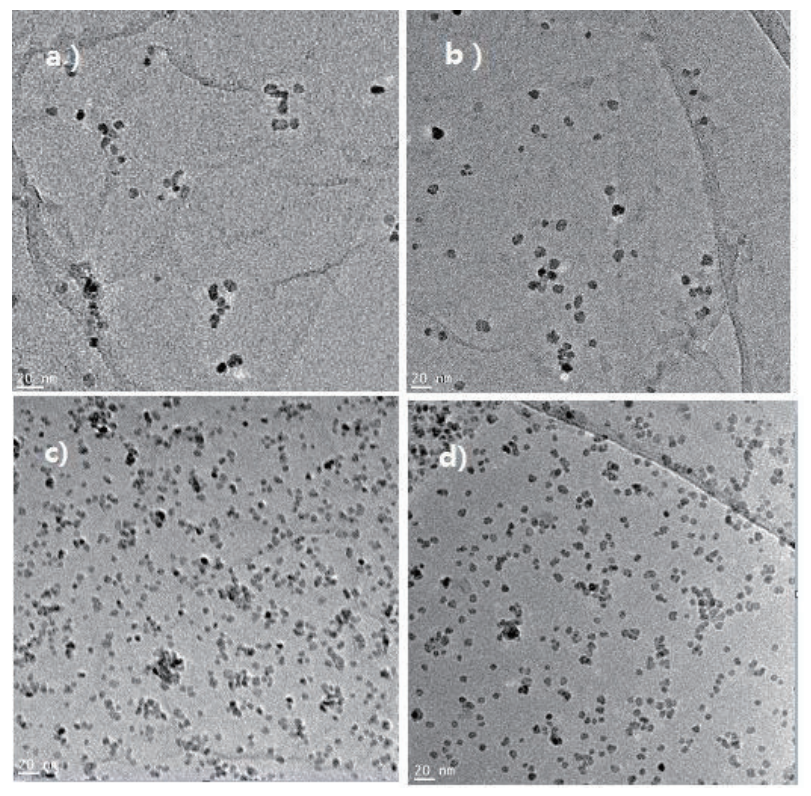

Fig. 5 TEM images of the as-prepared graphene $/ \mathrm{Co}_{3} \mathrm{O}_{4}$ composite with different reaction times. (a): $2 \mathrm{~h}$; (b): $5 \mathrm{~h}$; (c): $10 \mathrm{~h}$; (d): $15 \mathrm{~h}$. (oxidant: $30 \% \mathrm{H}_{2} \mathrm{O}_{2}$, reaction temperature: $150{ }^{\circ} \mathrm{C}$ ) )

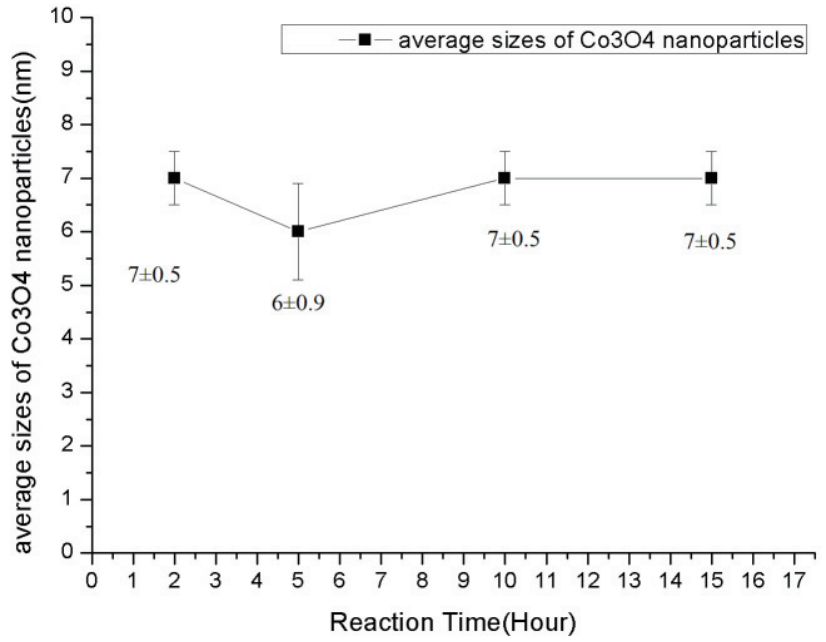

Fig. 6 the average sizes of $\mathrm{Co}_{3} \mathrm{O}_{4}$ nanoparticles with different reaction times

Fig. 7 is the HRTEM image of the Graphene/ $\mathrm{Co}_{3} \mathrm{O}_{4}$ nanocomposites using $\mathrm{H}_{2} \mathrm{O}_{2}$ as oxidant for $10 \mathrm{~h}$ at $120^{\circ} \mathrm{C}$. The interplanar distance measured as $0.20 \mathrm{~nm}$ is well coincident with it of (400) plane of $\mathrm{Co}_{3} \mathrm{O}_{4}$.

\section{CONCLUSIONS}

TEM and HRTEM have been employed to study the morphology of the obtained materials and the structure of the nanoparticles. We have demonstrated that $\mathrm{Co}_{3} \mathrm{O}_{4}$ nanoparticles under $10 \mathrm{~nm}$ can be obtained via the facile synthesis method we report. And the impact of the reaction time, temperature and oxidant on the microstructures of $\mathrm{Co}_{3} \mathrm{O}_{4}$ nanoparticles were investigated. The $\mathrm{Co}_{3} \mathrm{O}_{4}$ nanoparticles have a monodispersed grain size less than $10 \mathrm{~nm}$. The optimized reaction condition is using $\mathrm{H}_{2} \mathrm{O}_{2}$ as oxidant for $10 \mathrm{~h}$ at $120^{\circ} \mathrm{C}$.

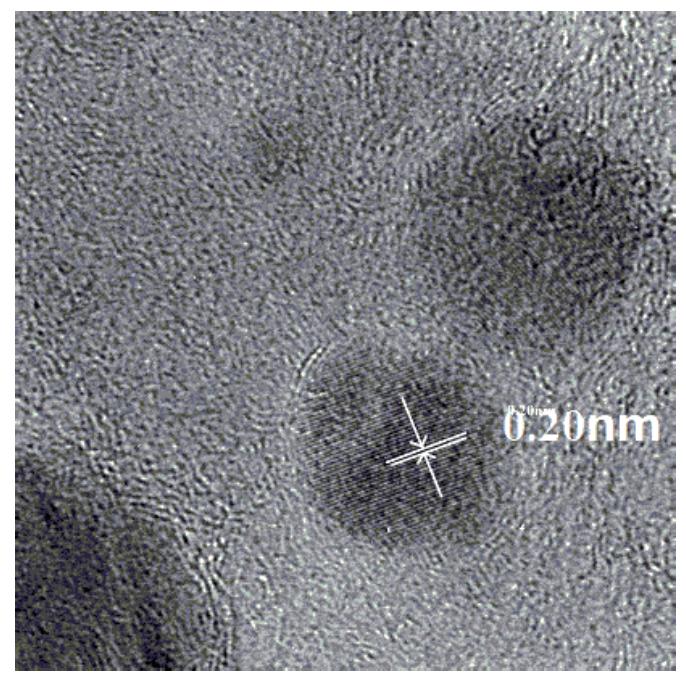

Fig. 7 HRTEM image of the Graphene $/ \mathrm{Co}_{3} \mathrm{O}_{4}$ nanocomposites 


\section{ACKNOWLEDGMENT}

This work was supported by the National Basic Research Program of China (Grant Nos. 2011CB707601 and 2009CB623702), the National Natural Science Foundation of China (Nos. 61274114 and 51071044).

\section{REFERENCES}

[1] W. Y. Li, L. N. Xu, J. Chen, " $\mathrm{CO}_{3} \mathrm{O}_{4}$ Nanomaterials in Lithium-Ion Batteries and Gas Sensors," Adv. Funct. Mater. vol. 15, 2005.

[2] N. Du, H. Zhang, B. Chen, J. B. Wu, X. Y. Ma, Z. H. Liu, et al., "Porous $\mathrm{Co}_{3} \mathrm{O}_{4}$ Nanotubes Derived from $\mathrm{Co}_{4}(\mathrm{Co})_{12}$ Clusters on Carbon Nanotube Templates: A Highly Efficient Material for Li-Battery Applications," Adv. Mater. vol. 19, pp. 4505-4509, 2007.

[3] W. L. Yao, J. Yang, J. L. Wang, Y. Nuli, "Multilayered Cobalt Oxide Platelets for Negative Electrode Material of a Lithium-Ion Battery," J. Electrochem. Soc. Vol. 115, pp. A903-A908, 2008.

[4] Y. G. Li, B. Tan, Y. Y. Wu, "Mesoporous $\mathrm{Co}_{3} \mathrm{O}_{4}$ Nanowire Arrays for Lithium Ion Batteries with High Capacity and Rate Capability," Nano Lett. Vol. 8, pp. 265-270, 2008.

[5] Z. S. Wu, W. Ren, L. Wen, L. Gao, J. Zhao, Z. Chen, et al., "Graphene Anchored with $\mathrm{Co}_{3} \mathrm{O}_{4}$ Nanoparticles as Anode of Lithium Ion Batteries with Enhanced Reversible Capacity and Cyclic Performance", ACS NANO, vol. 4, No. 6, pp. 3187-3194, 2010.

[6] W. S. Hummers, R. E. Offeman, "Preparation of graphitic oxide," J Am Chem Soc, vol. 80, No. 6, pp.1339-1339, 1958 